\title{
The improved design method of shear strength of reinforced concrete beams without transverse reinforcement
}

\author{
Pavlo Vegera, Rostyslav Vashkevych, Roman Khmil, Zinoviy Blikharskyy \\ Lviv National Polytechnic University \\ Department of Building construction and bridges, Institute of Building and Environmental Engineering \\ e-mail: pavlovegera@gmail.com,roman_hl@ukr.net
}

\begin{abstract}
In this article, results of experimental testing of reinforced concrete beams without transverse shear reinforcement are given. Three prototypes for improved testing methods were tested. The testing variable parameter was the shear span to the effective depth ratio. In the result of the tests we noticed that bearing capacity of RC beams is increased with the decreasing shear span to the effective depth ratio. The design method according to current codes was applied to test samples and it showed a significant discrepancy results. Than we proposed the improved design method using the adjusted value of shear strength of concrete $\mathrm{C}_{\mathrm{Rd,c}, \mathrm{T}}$. The results obtained by the improved design method showed satisfactory reproducibility.
\end{abstract}

Key words: design, shear strength, RC beam.

\section{Introduction}

Exploitation of reinforced concrete structures is widespread in the world. Studying their stress-strain state, improvement of design and construction principles, development of more effective methods for designing of bearing capacity is an important problem. For a long time, design standards were in use in Ukraine [10] which have been widely researched and elaborated for many years. With the implementation of Eurocode [1] in Ukraine, a lot of questions about their use had arisen. Development and implementation of the designing of standard cross sections of reinforced concrete elements were engaged by Ekenel M. [6], Ferrari V. [7]. In these works, the basic principles of designing of reinforced concrete elements for the action of bending moment according to the principles of the strain method are developed. Designing of RC beams on the action of shear force have to be performed according to the truss model and the design standard [1]. This designing principle was mainly researched abroad: Saeed M. [8], Bazant Z. [9]. In those articles and design standards there are no clear designations as to the use of individual coefficients, only their minimum values which leads to a significant over-consumption of materials. The research of a stress-strain state and principles of calculation of reinforced concrete beams on a shear is an important goal, considering the unexpected, fragile character of the destruction of such elements. 


\section{The aim and subject of research}

Based on the above stated, the aim of research is the experimental and theoretical determination of shear strength of reinforced concrete beams without the shear reinforcement and development of recommendations for the more accurate designing of shear strength.

Realization of the set aim of researches can be obtained by implementation of the following research tasks:

- to carry out experimental research of the shear strength of reinforced concrete beams with various shear spans;

- to improve the design method of shear strength of reinforced concrete beams;

Solving the preset tasks of research will allow to get the data about the real stress-stain state of reinforced concrete beams without the shear reinforcement.

The object of the research is bearing capacity of the RC beams on the shear.

The subject of the research - the improved design method of the shear strength of RC beams without transverse reinforcement.

The following research methods were used in this work: analysis of scientific references and design codes, experimental research of the RC beams on the shear; theoretical analysis of the experimental data.

\section{Experimental data and testing results}

\subsection{Material and construction of the samples}

Experimental samples of reinforced concrete beams were made with the length $2100 \mathrm{~mm}$ and dimensions of the cross-section $200 \times 100 \mathrm{~mm}$. The span of the prototype is $1900 \mathrm{~mm}$. All RC beams were accomplished in identical geometric sizes; the deviation was less than $2 \%$. The tensile reinforcement was by bars $\varnothing 18 \mathrm{~mm}$.; reinforcement in the compressed concrete zone by $\varnothing 10 \mathrm{~mm}$. and mounting smooth bars $\varnothing 8 \mathrm{~mm}$., located in the zone where there is no shear force. The scheme of reinforced RC beams is shown in Fig. 1.

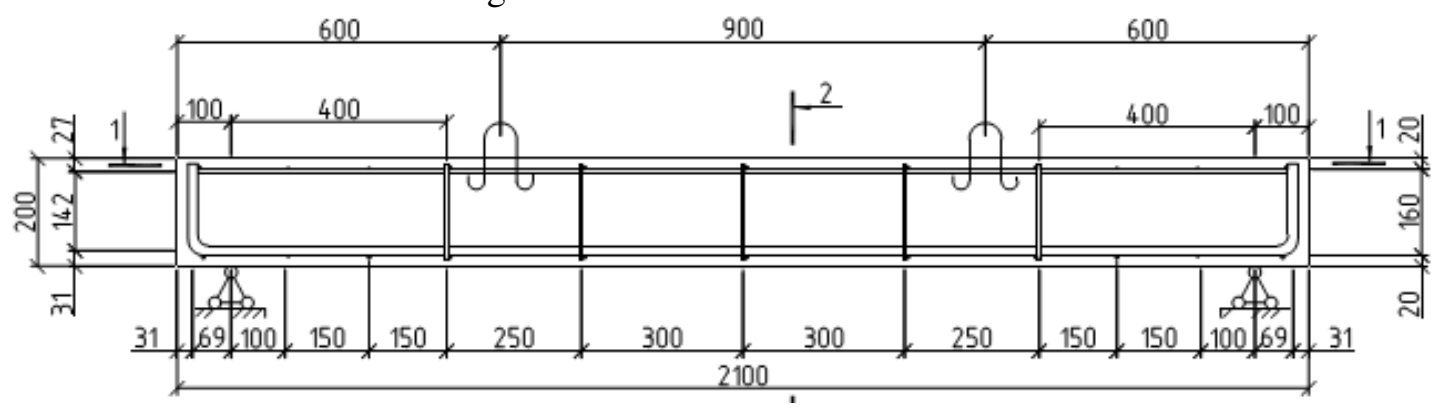

Figure 1: The reinforcement of the testing beam

During the production of beams, samples of reinforcement and samples of concrete were selected to obtain the real physical and mechanical characteristics of the materials. The characteristics of the reinforcing steel were determined by testing on tension the samples $400 \mathrm{~mm}$ in length, in three test specimens of each diameter. According to the results of the tests it can be concluded that the compressed and tension reinforcement belongs to the class A500C, whereas smooth reinforcement belongs to the class A240C. The determination of physical and mechanical characteristics of concrete was carried out using standard samples of cubes, prisms and cylinders. The samples were made from 
concrete of the same batch as the experimental beams. According to test results of concrete samples it is established that concrete belongs to class C32/40 [2].

Beams mark follows: BO - ordinary beam, the first digit - serial number, the second digit prototypes number and the third digit - section number. For example, BO 1.2-2 means that the second beam of the first series has been tested in the second section. The reinforced concrete beam was designed to provide ultimate moment resistance in accordance with the recommendations of the codes [3].

\subsection{Methodology of sampling}

The testing method involves testing one test sample twice. To do this for one supporting area the steel pre-stressed ring was mounted. In doing so, we investigate another inclined section (details are in [11]).

\subsection{Results of experimental investigations}

According to the developed methodology there were tested $3 \mathrm{RC}$ beams without the shear reinforcement. A variable parameter was accepted the shear distance (a) to effective depth (d) ratio, which acquired the values: $\mathrm{a} / \mathrm{d}=2, \mathrm{a} / \mathrm{d}=1.5, \mathrm{a} / \mathrm{d}=1$.

As the criterion of exhaustion of bearing capacity of the cross-section there were taken achievements of concrete compressed strain limit at the section above the inclined crack in the direction of the main compressive stresses [3].

Regardless of the shear span the first inclined crack appears in mid-height cross section at the loading $50 \mathrm{kN}$ and at an angle equal to $45^{\circ}$. At the next stage the inclined crack spread to the bottom edge of the beam. With the increasing loading crack the width increases and the crack develops to the top edge of the sample (Fig. 2). On the occurrence of limit crack width $w=0.4 \mathrm{~mm}$, another crack opens in the direction from the point of application loading and develops to the edge of the support (Fig. 2a). This was the destructive crack. The inclined crack develops throughout the height of the beam, and then the shear of compressed zone of the concrete and concrete crushing occurred. Further the longitudinal reinforcement received large deformations and bending. For the beams BO 1.2 and BO 1.3 there was occurrence only of one inclined crack. It has been developing more slowly due to the increasing impact of the compressive forces in the section with decreasing of a shear span (Fig. 2b, 2c).

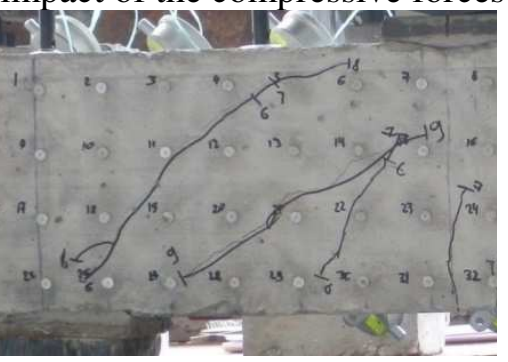

a)

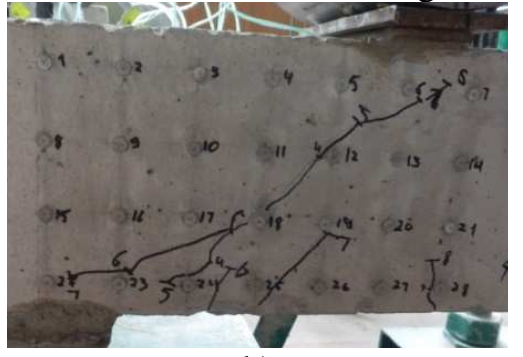

b)

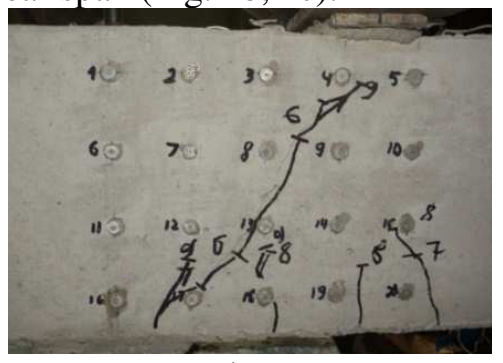

c)

Figure 2: Developing of inclined cracks in the samples: a) BO 1.1; б) BO1.2; в) BO 1.3

The shear strength of RC beams was: for beam BO $1.1-V_{E Q}=95 \mathrm{kN}$; BO $1.2-V_{\text {Ia }}=140.5 \mathrm{kN}$; BO $1.3-V_{E d}=140.5 \mathrm{kN}$ which indicates increasing of the strength with decreasing of the shear distance to the effective depth ratio. 
The results convergence of experiments data of each side (left and right) of the tested beam was satisfactory $5 \ldots 9 \%$ which indicates the high reliability of obtained results and the effectiveness of the proposed research methodology. The general view of the tested specimens is shown in Fig. 3.

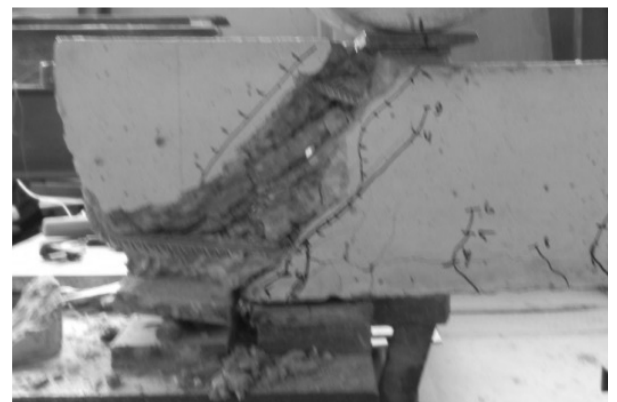

a)

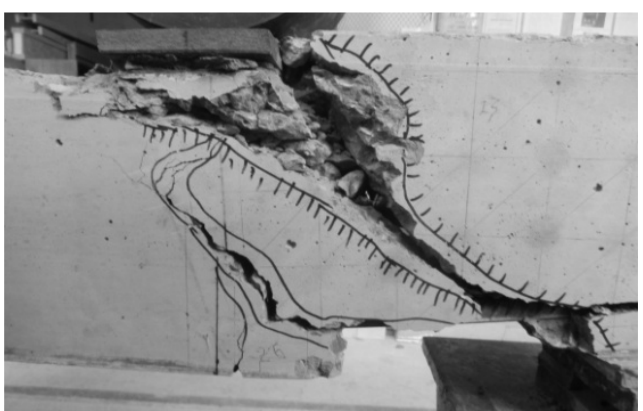

b)

Figure 3: The specimens after testing: a) BO 1.1; b) BO 1.3

The experimental results of the comparative analysis of the shear strength of beams are shown in Table 1.

Table 1: The shear strength of beams without the transverse shear reinforcement

\begin{tabular}{|c|c|c|c|c|c|c|c|}
\hline $\begin{array}{l}\text { Marks } \\
\text { beam }\end{array}$ & $\begin{array}{c}\text { № side of } \\
\text { beam }\end{array}$ & $\begin{array}{l}\text { Cross section } \\
\mathrm{b} \times \mathrm{h} \mathrm{mm}\end{array}$ & $\begin{array}{c}\text { Span of } \\
\text { beam } \\
1_{0} \mathrm{~mm}\end{array}$ & $\begin{array}{c}\text { Shear span } \\
\text { to effective } \\
\text { depth ratio, } \\
\text { a/d }\end{array}$ & $\begin{array}{c}\text { Shear } \\
\text { strength of } \\
\text { RC beam, } \\
V_{E u}^{e x p}, \mathrm{KN}\end{array}$ & $\begin{array}{c}\text { Average } \\
\text { value of } \\
\text { bearing } \\
\text { capacity, } \\
v_{\mathrm{Ed}}^{\in x, a v}, \mathrm{\kappa N}\end{array}$ & $\begin{array}{c}\text { Increasing } \\
\text { shear strength } \\
V_{E d}^{a x p a n} \\
V_{E d}^{B O 1.1}\end{array}$ \\
\hline \multirow{2}{*}{ BO 1.1} & BO 1.1.1 & \multirow{2}{*}{$201 \times 106$} & 1900 & \multirow{2}{*}{2} & 97 & \multirow{2}{*}{95} & \multirow{2}{*}{-} \\
\hline & BO 1.1.2 & & 1550 & & 93 & & \\
\hline \multirow{2}{*}{ BO 1.2} & BO 1.2.1 & \multirow{2}{*}{$199 \times 98$} & 1900 & \multirow{2}{*}{1.5} & 139 & \multirow{2}{*}{140.5} & \multirow{2}{*}{1.48} \\
\hline & BO 1.2.2 & & 1750 & & 142 & & \\
\hline \multirow{2}{*}{ BO 1.3} & BO 1.3.1 & \multirow{2}{*}{$202 \times 98$} & 1900 & & 192 & \multirow{2}{*}{198} & \multirow{2}{*}{2.08} \\
\hline & BO 1.3.2 & & 1650 & & 204 & & \\
\hline
\end{tabular}

According to the results of experimental tests there was recorded an increase of the shear strength in 1.48 times with decreasing of the shear span to the effective depth ratio from $\mathrm{a} / \mathrm{d}=2$ to $\mathrm{a} / \mathrm{d}=1.5$ and when $\mathrm{a} / \mathrm{d}=1$ the increasing of the shear strength was 2.08 times.

\section{Theoretical data and design results}

\subsection{Design methodology}

The current design standards [1-3] regulate the calculation shear strength by the truss model. The shear strength of beams without the shear reinforcement we calculate as the concrete strength on the shear at an angle equal to $45^{\circ}$.

The shear strength of RC beams is considered in accordance with condition (1). 


$$
V_{E d}<V_{n a, c}
$$

where $V_{E d}-$ the design value of the shear force from the external load. The design value of the shear force that can be taken by a cross-section without shear reinforcement, according to the standards [1$3]$, is determined by the equation:

$$
V_{R d, c 1}=\frac{\left[C_{R d, c} \cdot k \cdot\left(100 \cdot \rho_{1} \cdot f_{c k}\right)^{\frac{1}{3}}\right] \cdot b_{w} \cdot d}{\beta}
$$

However, at a value not less than:

$$
V_{R d, c 2}=v_{\min } \cdot b_{w} \cdot d
$$

where $C_{R d, c}$ - strength of concrete on a shear [5], by the standards [1], [3] it is recommended to take $0.18 ; k$ - coefficient of influence of beam height; $\rho_{l}$ - coefficient of reinforcement; $A_{s l}$ - cross sectional area of tensile reinforcement, $\mathrm{mm}^{2}, f_{c k}$ - characteristic compressive strength of concrete at 28 days, MPa; $b_{w}, d$-respectively, the smallest section width in the tensile zone and effective depth of a cross-section, mm; $v_{\min }$ - the minimum value of the shear strength, which may lead to fracture to yield strength in the longitudinal reinforcement, MPa.

Longitudinal reinforcement was taken into account only if it was placed at a distance $l_{b d}$ of the projection of the section considered at an angle $45^{\circ}, l_{b d}$ - minimum required length for anchoring of the longitudinal reinforcement.

The coefficient $\beta$, which is equal $\beta=a_{1} / 2 d$ and is introduced at loading design elements from above in the range of $0.5 d \leq a_{v} \leq 2 d$, as a decreasing coefficient of shear force $V_{E d}$. In this case it is recommended that it is introduced into the calculating apparatus for determining the bearing capacity of concrete $V_{R d, c l}$, by dividing the specified bearing capacity by this coefficient.

When using the coefficient $\beta$, the condition must be fulfilled:

$$
V_{E d} \leq 0.5 \cdot b_{w} \cdot d \cdot v \cdot f_{c d}
$$

where $f_{c d}$ - design value of concrete compressive strength, MPa; $v$ - strength reduction factor for concrete cracked in a shear.

The overestimation of experimental results in comparison with the theoretical ones is significant. The analysis of the results shows that one of the main factors that led to such a discrepancy is the inclusion of the incorrect strength of concrete on the shear $C_{R d, c}$ with the constant value of $0.18 \mathrm{MPa}$, regardless of the class of concrete.

To determine the impact of concrete strength on the shear we propose to use the dependence recommended by the European standards of the 1997 edition which takes into account the change in the strength of concrete on the shear from the axial tensile concrete strength [4]:

$$
C_{R d, c}=\tau_{R d}=0.25 \cdot f_{c t k 0.05}
$$

But, as we know, the main parameter of concrete is the compressive strength, therefore, in dependence (5) we turn from the axial tensile strength to compressive strength according to the dependencies given in the same standards:

$$
\begin{aligned}
& f_{c t k 0.05}=0.7 \cdot f_{c t m} \\
& f_{c t m}=0.3 \cdot f_{c k}^{2 / 3}
\end{aligned}
$$

As a result, we obtain the following dependence for the strength of the concrete on the shear:

$$
C_{R d, c}=0.0525 \cdot \sqrt[3]{f_{c k}^{2}}
$$

The results of calculation, in accordance with the current standard $[1,3]$ and using the specified value of the concrete strength on the shear, are shown in Table 2. 
Table 2: Designing results of shear strength of beams without the shear reinforcement

\begin{tabular}{|c|c|c|c|c|c|c|}
\hline \multirow{2}{*}{$\begin{array}{c}\text { Marks } \\
\text { beam }\end{array}$} & \multirow{2}{*}{$\begin{array}{c}\text { Shear span } \\
\text { to } \\
\text { effective } \\
\text { depth } \\
\text { ratio, a/d }\end{array}$} & \multirow{2}{*}{$\begin{array}{c}\text { Experimental } \\
\text { shear strength, } \\
V_{E d}(\mathrm{Q}), \mathrm{kN}\end{array}$} & \multicolumn{2}{|c|}{$\begin{array}{l}\text { Theoretical strength on shear } \\
\text { according to standard [3] }\end{array}$} & \multicolumn{2}{|c|}{$\begin{array}{l}\text { Theoretical strength shear } \\
\text { with } C_{R H_{2},} \text { defined by the } \\
\text { dependence ( } 8 \text { ) }\end{array}$} \\
\hline & & & $\begin{array}{c}V_{R d, c l}, \\
\mathrm{\kappa H} \\
\end{array}$ & $\frac{V_{E d}}{V_{R d . C \perp}}$ & $\begin{array}{c}V_{R d, c l}, \\
\mathrm{\kappa H}\end{array}$ & $\frac{V_{E d}}{V_{R d, \varepsilon z}}$ \\
\hline BO 1.1 & 2 & 95 & 32.8 & 2.89 & 81.6 & 1.16 \\
\hline BO 1.2 & 1,5 & 140.5 & 43.7 & 3.22 & 108.8 & 1.29 \\
\hline BO 1.3 & 1 & 198 & 65.5 & 3.02 & 163.2 & 1.21 \\
\hline
\end{tabular}

The designing results of shear strength of RC beams with the using of the specified values $C_{\bar{R} \text {, },}$ determined by the dependence (8) showed significantly a higher convergence. The overestimation of experimental data over the theoretical is $16 \ldots 29 \%$, which is permissible one, especially knowing the sharp character of the destruction beams without the shear reinforcement.

\section{Conclusions}

Based on the material above, the following conclusions can be formulated:

- the shear strength of RC beams without shear reinforcement increases with decreasing of the ratio shear span to the effective depth ratio (d/a). It can be used for a more efficient design of reinforced concrete elements;

- the overestimation of shear strength of RC beams without the shear reinforcement designed by the current standard under experimental results is significant up to $202 \%$;

- the improved design method is proposed and it provides results with a deviation from the experimental data of less than $29 \%$. This result allows designing structures which are more cost effective.

\section{References}

[1] EN 1992-1-1:2004 (E) Eurocode 2: Design of concrete structures - Part 1-1: General rules for buildings. Brussels, GEN, 2004.

[2] DBN B.2.6-98: 2009 Concrete and reinforced concrete construction. Kyiv, Minbudrehion Ukraine, 2011.

[3] DSTU B.V.2.6-156: 2010 Concrete and reinforced concrete construction with heavy concrete. Kyiv, Minbudrehion Ukraine, 2011.

[4] DD ENV 1992-1-1:1992 (E) Eurocode 2: Design of concrete structures - Part 1: General rules and rules for buildings (together with United Kingdom National Application Document). London, BSI, 1992.

[5] Amadio C., Macorini. L, Sorgon S., Suraci G.A novel hybrid system with RC-encased steel joints. EJECE. Vol.15, №10, 2011, P.1433-1463.

[6] Ekenel M., Rizzo A., Myers J.J., Nanni A. Flexural fatigue behaviour of reinforced concrete beams strengthened with FRP fabric and procured laminate systems. Journal of composites for construction, vol.1, 2006, P.433-442. 
[7] Ferrari V.J. J.B. De Hanai Flexural strengthening of reinforced concrete beams with carbon fibres reinforced polymer (CFRP) sheet bonded to a transition layer of high performance cement-based composite. Ibracon structural and materials journal. V.5 №5. 2012, P. 596-626.

[8] Saeed M.M. Torsion, shear and bending in reinforced concrete beams.: dis. - McGill University 1962. - 353p.

[9] Bazant Z.P, Kazemi M.T. Size effect on diagonal shear failure of beams without stirrups. ACI Structural journal, V.88 №3, 1991, P.268-276.

[10] SNiP 2.03.01-84* Betonni ta zalizobetonni konstrukciy NIIGB Gosstroy SSSR Moscov, 1986.

[11] Vegera P.I., Khmil R.Y., Blikharskyy Z.Z. Optimization methodology of experimental research of inclined cross sections of reinforced concrete beams. Theory and practice of building, №823, 2015, P.38-43. 